\title{
A VOZ DO ALUNO NO PROCESSO DE EDUCAÇÃO À DISTÂNCIA: REENGENHARIA DO CURSO “CONHECENDO O IBGE” COM BASE EM AVALIAÇÕES DOS DISCENTES.
}

\author{
RIO DE JANEIRO/RJ JULHO/2018 \\ Hugo Sousa Campos - IBGE - hugo.campos@ibge.gov.br \\ Tipo: Relato de Experiência Inovadora (EI) \\ Categoria: Métodos e Tecnologias \\ Setor Educacional: EDUCAÇÃO CORPORATIVA
}

\begin{abstract}
RESUMO
O curso à distância "Conhecendo o IBGE" tem como seu principal público os servidores do próprio Instituto, principalmente, aqueles que estão chegando à Instituição ou que vão assumir algum cargo de gerência. A primeira edição do curso foi implementada em 2015, no entanto, com base nas avaliações dos mais de 300 alunos que foram capacitados, a Coordenação de Treinamento e Aperfeiçoamento do IBGE, em parceria com a Coordenação de Recurso Humanos, propôs a reengenharia do mesmo, conferindo voz aos discentes, neste processo de reformulação. O presente artigo aborda as estratégias utilizadas no redesenho da solução educacional, bem como as metodologias aplicadas e inovações inseridas pela equipe multidisciplinar a cargo da educação corporativa no IBGE.
\end{abstract}

Palavras-chave: educação a distância; IBGE; avaliação; desenho instrucional; reengenharia 


\section{Introdução}

O Instituto Brasileiro de Geografia e Estatística (IBGE) é bastante conhecido por grande parte da sociedade. O sentimento de familiaridade com a sigla é aditivado pelas diversas notícias, publicadas e explicitadas, diariamente, com base nas pesquisas apresentadas pelo Instituto: "IBGE mostra números dramáticos do mercado de trabalho em 2016"; "IBGE: Mulher estuda mais, trabalha mais e ganha menos do que o homem"; "Concluir o ensino superior triplica a renda, mostra IBGE"; "Inflação oficial desacelera e fica em 0,09\% em março, diz IBGE"; "IBGE revê altitude de sete picos brasileiros: o da Neblina fica mais alto".

O ponto em comum em todas as manchetes, acima reproduzidas, reside no fato de terem reforçado que a informação não é originária dos próprios veículos de imprensa e sim de uma instituição de mais de 80 anos, confiável e consistente em suas pesquisas. E é justamente este reconhecimento que confere o peso que se pretende emanar de tais matérias.

Todavia, o fato de sermos cercados, de tão perto, pelo IBGE e suas produções estatísticas e geocientíficas, pode aflorar a percepção de que conhecemos bem a instituição e a sua importância para o Brasil. Sabe-se que o IBGE realiza o Censo e também a Pesquisa Nacional por Amostra de Domicílios Contínua (PNAD Contínua), menina dos olhos do noticiário nacional. Mas o IBGE não se resume ao Censo Demográfico e à PNAD. Existe um grande número de informações, nem sempre noticiadas, mas de extrema relevância para o país, as quais auxiliam na tomada de decisões estratégicas e formulação de políticas públicas.

Assim, com a finalidade de aprimorar a disponibilização de conhecimento sobre o Instituto, a Coordenação de Treinamento e Aperfeiçoamento da Escola Nacional de Ciências Estatísticas (ENCE), em parceria com a Coordenação de Recursos Humanos, iniciou, em 2015, projeto para elaboração de um curso sobre a Instituição, cujo nome foi definido como Conhecendo o IBGE. Tratou-se de uma experiência pioneira que visava capacitar todos os servidores - principalmente os novos, temporários e aqueles que iam assumir algum cargo de gerência - sobre o Instituto, suas pesquisas e sua relevância para a sociedade.

O curso, em formato de PDFs disponibilizados no Ambiente Virtual de Aprendizagem (AVA) da Escola Virtual IBGE, esteve no ar durante dois anos (2015 a 2017), no entanto, os feedbacks dos alunos impulsionaram a revisão do mesmo e o lançamento de uma nova versão, em 2018, no formato HTML. Este artigo, portanto, irá relatar como foi esta 
experiência inovadora de reengenharia de um curso totalmente em PDF para uma plataforma mais interativa, a qual se utiliza dos recursos e das potencialidades da linguagem em HTML para a oferta de soluções educacionais.

\section{Objetivo}

Este artigo tem como objetivo relatar a experiência de reformulação do curso EaD, Conhecendo o IBGE, destacando as etapas de planejamento, desenvolvimento, implementação e avaliação da solução de capacitação. Desta forma, pretende chamar a atenção para a importância da construção de processos de avaliação onde as experiências dos discentes são analisadas e incorporadas.

\section{Referencial teórico}

O termo "reengenharia" conceituado e introduzido no campo da Administração por Michael Hammer e James Champy, em 1993, significa repensar e redesenhar as práticas e processos da estrutura organizacional (HAMMER; CHAMPY, 1994). Todavia, pode ser igualmente aplicado ao universo educacional, à medida que reengenharia não se trata de uma simples reorganização. Não significa apenas organizar novamente, mas sim reavaliar, replanejar, reinventar, reestruturar, reprojetar (LEAL, 2010, p.14). A Reengenharia do Conhecendo IBGE foi um processo minucioso, pois trabalhou-se sob um plano já existente, com uma estrutura já formada, uma organização já constituída. $E$ nisto reside o desafio de qualquer procedimento de reengenharia.

No processo de reengenharia do curso foi adotado o princípio da multimídia, tal qual proposto por Andrea Filatro, ao destacar que "o aprendizado eletrônico deve incluir tanto textos quanto gráficos, e não apenas um desses dois tipos de informação" (2008, p.74). Devemos, portanto, considerar que os alunos aprendem bem mais quando estas informações são combinadas.

\section{Procedimentos metodológicos}

Dentre os procedimentos metodológicos aplicados ao trabalho desenvolvido, destacamse as seguintes etapas:

\subsection{Etapa de análise do curso a ser reformulado}

Para analisar a versão anterior do curso, utilizamos os dados das avaliações e impressões dos discentes, relativas às 11 turmas concluídas de 2015 a 2017. Esta 
avaliação, facultativa, geralmente é preenchida ao final da capacitação. A fonte de dados foi o ambiente de aprendizagem da Escola Virtual IBGE, repositório de tais informações.

Dos 1.229 alunos, distribuídos pelas 11 turmas, 331 (cerca de 26\%) realizaram a avaliação do curso. Todas estas contribuições foram lidas e consideradas para definir o novo formato e as estratégias de apresentação do conteúdo. Nas 331 avaliações, os alunos apresentaram diversas considerações como elogios ao curso, dificuldade de conciliar o mesmo com as atividades de trabalho ou solicitação de tutoria. No entanto, os temas mais recorrentes foram acerca da estruturação e apresentação do conteúdo (14\%) e sobre críticas à avaliação final (8\%), definida por muitos como "decoreba" e com questões "desnecessárias".

Destacamos, a seguir, algumas contribuições que representavam o forte clamor pela reengenharia do curso: "Sugiro a utilização de mais recursos de videoaulas"; "A forma de conteúdo ficou bastante carregada, propiciando certo cansaço ao aluno"; "Achei a primeira parte do curso muito conceitual e desgastante"; "O modelo de entrega do conteúdo é muito cansativo. Apenas ler um PDF é muito cansativo. Contudo os vídeos quebram um pouco este problema".

Desta forma, ficou evidente que a reengenharia do curso deveria, prioritariamente, focar na forma como o conteúdo seria apresentado e também em quais temas seriam ou não abordados. Como consequência desta análise, a avaliação final seria inexoravelmente refeita. E por meio desta estratégia de reformulação da capacitação, os problemas mais destacados pelos discentes receberiam uma atenção maior.

Assim, como área de capacitação de um Instituto de Estatísticas, concordamos com Ivete Palange quando afirma que "consultar uma pequena amostra do grupo que será atendido permite conhecer melhor o universo do público e de suas formas de aprendizagem" (2015, p. 260). É extremamente importante dar voz ao discente e estar atento às sugestões e opiniões. É possível que estas não se apliquem e não sejam as mais adequadas para o curso em questão, todavia, podem orientar novas produções e contribuir para a consolidação de um sistema eficaz de ensino-aprendizagem.

\subsection{Etapa de planejamento do novo curso}

A fim de conhecer o novo contexto no qual o curso seria implementado, compuseram o relatório de análise contextual: as necessidades de aprendizagem; a caracterização dos alunos; o levantamento de restrições e encaminhamento a soluções (FILATRO, 2008, 
p.38).

$\mathrm{Na}$ etapa de planejamento da capacitação, foi efetuado um cuidadoso estudo com vistas à reengenharia que se pretendia iniciar. Nesse estudo, descobrimos que a visão do IBGE que se pretendia transmitir, no curso, estava centrada apenas na produção de informações estatísticas e geocientíficas. Havia quase uma total ausência de conteúdos acerca da disseminação destas informações, que é o cerne da missão do Instituto, o qual não apenas produz e engaveta, mas produz para a sociedade: governos, comunidade acadêmica, cidadãos, dentre outros que desejam conhecer a realidade do seu país. Assim, os conteudistas foram acionados para a elaboração de conteúdo adicional e revisão do existente, a fim de que as lacunas encontradas fossem supridas e que o curso apresentasse integralmente o IBGE e não apenas os produtos e áreas que possuem maior visibilidade dentro da Instituição.

De posse de um conteúdo reformulado, procedeu-se à reorganização dos módulos e unidades estudo. Foi elaborada uma nova matriz instrucional e os objetivos de aprendizagem foram todos revistos. No redesenho do curso, atendendo às solicitações dos alunos, foram selecionadas mídias mais interativas. Textos de mais de 30 páginas sobre a história dos Censos, por exemplo, na nova versão do curso, foram substituídos por uma linha do tempo mais interativa, com fotografias relativas às operações censitárias e os números de habitantes apurados.

Uma outra estratégia de ensino adotada foi a utilização de uma seção, em todas as unidades do curso, intitulada "O IBGE na mídia", que ajuda o discente a relacionar o trabalho do Instituto com fatos concretos que ocorrem na sociedade. Afinal, por trás dos números existem seres humanos, sonhos, modos de ser e fazer, vitórias e fracassos que marcam uma sociedade ou uma geração. Também foram incorporados depoimentos dos servidores sobre suas atividades no IBGE, dando mais vida à forma como as estatísticas são produzidas. Estas constituem-se estratégias de apresentação de um conteúdo significativo e que dialoga com a realidade do discente, a fim de favorecer a aprendizagem.

Nos últimos anos, a área de disseminação do IBGE avançou bastante na produção de vídeos e estes foram incorporados no redesenho do curso, a fim de consolidar a explicação sobre determinada pesquisa ou procedimento metodológico. Isso porque “(...) o áudio tem o poder de aumentar os níveis de atenção, a taxa de retenção, as respostas emocionais e a ênfase às mensagens, além de prover, quando necessário, alguma sensação de alívio" (PISKURICH, 2006). Um exemplo foi a inserção de vídeo sobre o Censo Agropecuário, para ajudar na compreensão acerca das pesquisas 
agropecuárias do IBGE como a Pesquisa Trimestral do Leite, do Couro, a Pesquisa de produção de Ovos de Galinha e a Pesquisa trimestral de abate de animais.

Figura 1 - Vídeo sobre o Censo Agropecuário, incorporado à Unidade 2 da nova versão do Curso Conhecendo o IBGE.

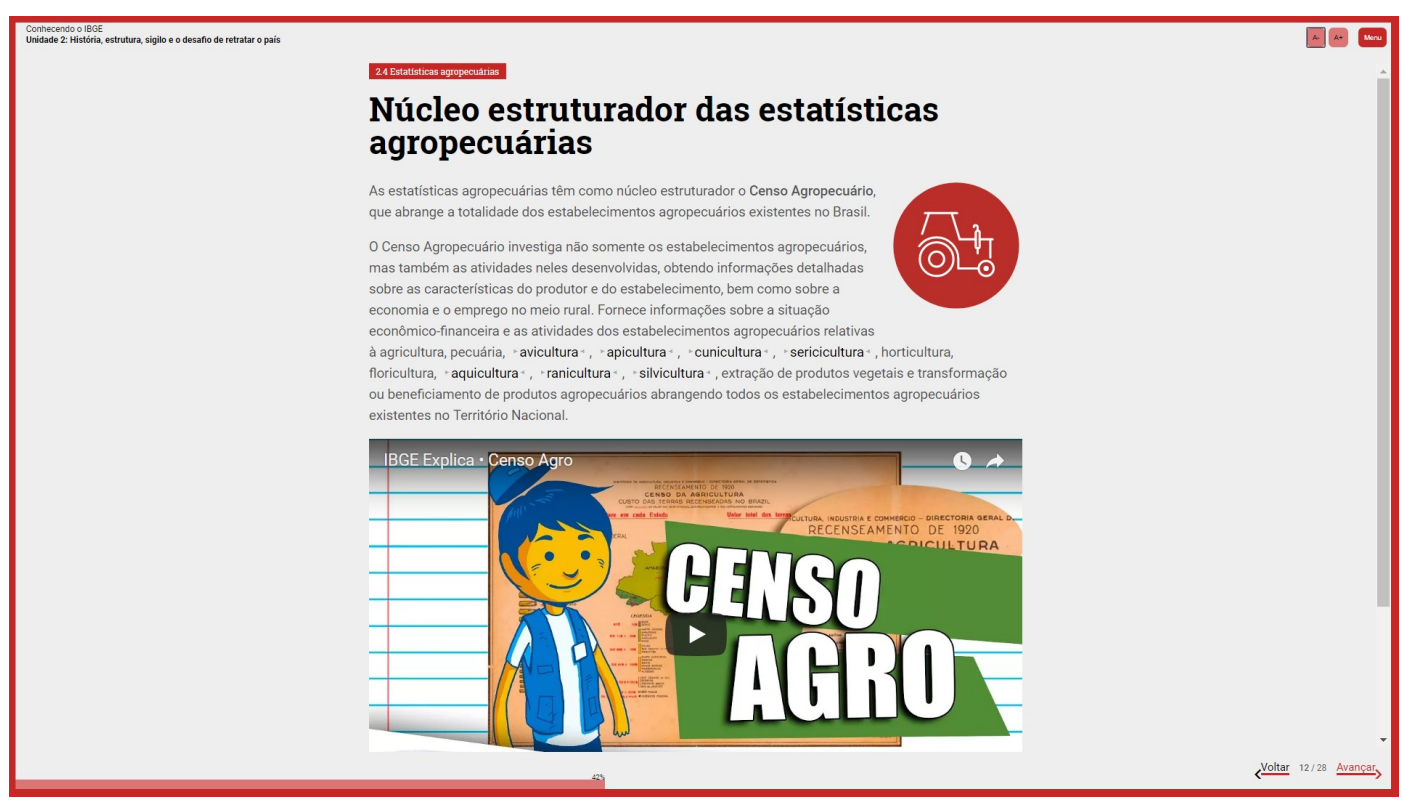

Fonte: Escola Virtual IBGE

\subsection{Etapa de produção do curso}

$\mathrm{Na}$ etapa de produção do curso, utilizamos o storyboard como instrumento de trabalho, que pode ser compreendido como uma:

“(...) ferramenta amplamente difundida entre os designers instrucionais (...), que permite descrever e ordenar as interações previstas entre o aluno e o recurso, além de representar a estrutura da informação e indicar a presença e a posição de elementos textuais, auditivos e visuais e serem utilizados" (SANTOS, Cristiane, 2015, p.307)

Para a construção dos storyboards, efetuamos a leitura do conteúdo bruto; e juntamente com o núcleo de design gráfico, buscamos referências visuais (fotos, ilustrações, diagramas e charges). Uma preocupação constante, ao longo da roteirização, foi a escolha de imagens com finalidade pedagógica. Perseguimos a busca pela utilização para compreensão do conteúdo e não para ilustrar ou deixar a página mais bonita.

Os storyboards facilitaram o processo de validação do curso por parte dos conteudistas, uma vez que estes conseguiam perceber como o conteúdo foi estruturado e qual a 
sequência dos temas. Foi uma ferramenta essencial, considerando que o projeto possui uma considerável rede de validadores e que os temas foram apreciados pelos respectivos especialistas do IBGE nos assuntos que estavam sendo abordados. Esta fase foi vista como um grande desafio, no sentido de conciliar gostos, hierarquização da informação, preferências e estilo de redação, mas que produziu um resultado muito positivo, que efetivamente denota um trabalho em equipe.

Quando se opta pela aprendizagem autodirigida, "o designer instrucional deve ter atenção especial com a qualidade do material educacional oferecido ao aprendiz" (PALANGE, 2015, p.241), isso porque, nestes casos, há baixa intervenção de tutoria. Pensando na importância desta qualidade, é correto dizer que o projeto Conhecendo o IBGE foi beneficiado pela implantação de um novo Sistema de Design. O núcleo de design da Coordenação de Treinamento e Aperfeiçoamento da ENCE, ainda na fase de planejamento, apresentou uma proposta para uniformização e criação de uma identidade visual, dos cursos, apostilas, slides e demais materiais pedagógicos, utilizados tanto em capacitações presenciais quanto à distância. O Conhecendo o IBGE foi o primeiro curso a se beneficiar deste Sistema de Design, o que proporcionou agilidade e coerência visual na etapa de desenvolvimento.

$\mathrm{Na}$ fase de produção, com auxílio dos conteudistas, procedemos com a reformulação da avaliação final do curso, conforme sugestões dos alunos. Foram propostas questões mais atuais, dialogando com charges, reportagens, músicas, com foco no estabelecimento de relações entre os temas apresentados, análise contextual e interpretação de texto.

\section{Apresentação e discussão dos resultados}

O curso reformulado, após 4 meses - envolvendo as etapas de análise, desenho e desenvolvimento - teve a sua primeira turma implementada em maio de 2018. Os integrantes da turma foram 33 servidores do IBGE, os quais participam da sétima edição do Programa de Desenvolvimento de Liderança nas Agências do IBGE e necessitam da aprovação no Conhecendo o IBGE para prosseguimento no programa, composto de mais 4 cursos e um projeto final. Os alunos participantes foram indicados pela Coordenação de Recursos Humanos.

Considerando que, no momento de fechamento deste artigo, ainda nos encontrávamos em fase de implementação, não possuímos o feedback completo da primeira turma, após a reengenharia do curso. No entanto, com base em avaliações dos alunos que já 
concluíram, é possível vislumbrar uma melhora nos índices de satisfação quanto à usabilidade. Hipótese que será ratificada somente após a análise de todas as avaliações da nova versão.

Todavia, é bastante nítido o salto de qualidade que o curso alcançou com a sua disponibilização no formato em HTML e com a implantação de um Sistema de Design. Tal fato pode ser notado na imagem a seguir, onde é possível observar as capas do curso, em sua antiga versão, no formato PDF, e a capa da nova versão no formato HTML, passível de ser acessada em diferentes dispositivos e navegadores.

Figura 2 - À esquerda, a capa da Unidade 4 do curso Conhecendo o IBGE, em sua antiga versão, no formato PDF e à direita a nova capa no formato HTML.

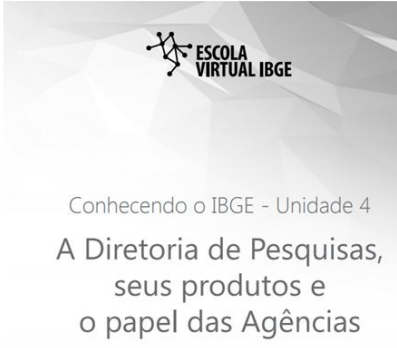

IBGE

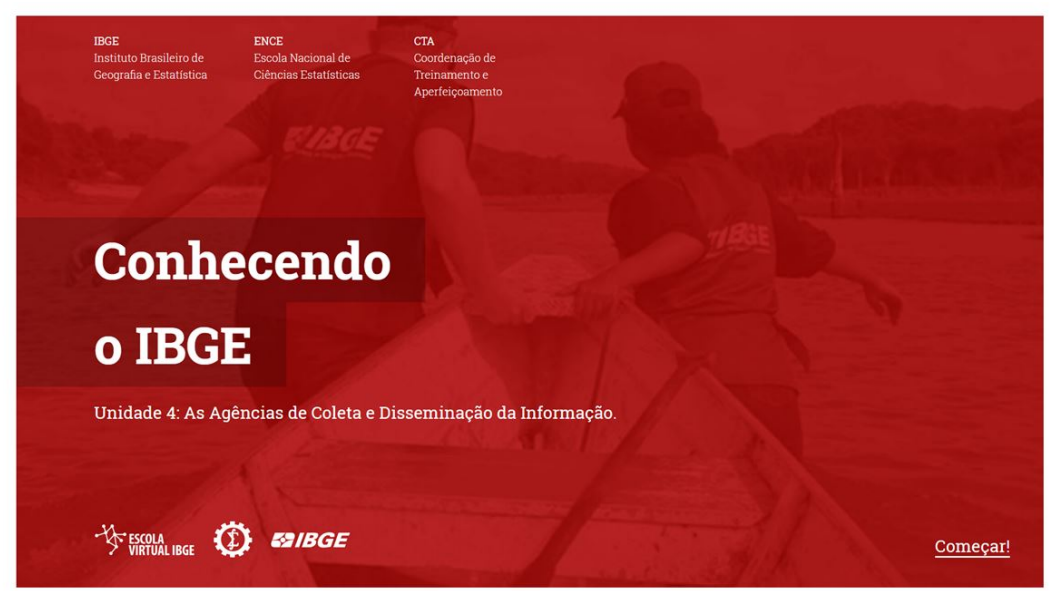

Fonte: Escola Virtual IBGE

\section{Considerações finais}

Segundo Ivete Palange, o objetivo da avaliação de um projeto “(...) não é encontrar culpados por possíveis problemas ou fracassos, mas identificar os pontos fracos que precisam ser melhorados e os pontos forte que poderão ser aproveitados em novas experiências" (2015, p.267)

Com esta afirmativa, a autora destaca bem o que significa um trabalho de reengenharia semelhante ao empreendido no curso Conhecendo o IBGE. A identificação dos pontos que precisavam ser melhorados, com base na análise das avaliações dos discentes, conferiu voz aos mesmos e resultou em uma construção conjunta, que busca atender às necessidades e expectativas deste novo público conectado, consumidor massivo de informações interativas e desejoso que os treinamentos corporativos na modalidade EAD não se distanciem tanto do seu dia a dia na rede mundial de computadores. 
Inês Messias e Lina Morgado ratificam esta ideia, quando defendem que "Numa sociedade que se diz digital, saber usar as ferramentas disponíveis de forma eficaz é uma necessidade, mais ainda para o estudante que frequenta o Ensino a Distância (EaD) ou o ensino mediado pela tecnologia" (MESSIAS; MORGADO, 2018).

O presente relato de uma experiência reengenharia de curso à distância, busca chamar a atenção para $o$ fato de que 0 trabalho do designer instrucional não termina quando 0 curso é disponibilizado no AVA. Este profissional deve se debruçar nas avaliações dos alunos, analisar os pontos fortes e fracos do curso, propor mudanças e retornar para a fase de análise e planejamento, em um ciclo constante, a caminho das melhores e mais poderosas práticas educacionais.

Neste sentido, entendemos que somente uma equipe multidisciplinar de designers, pedagogos, professores, administradores, psicólogos, dentre outros, e a pluralidade de olhares e contribuições são capazes de produzir materiais riquíssimos e conduzir os discentes a experiências efetivas de aprendizado significativo e não apenas à obtenção de mais um certificado de conclusão de curso.

\section{Bibliografia}

Agência Brasil. IBGE revê altitude de sete picos brasileiros: o da Neblina fica mais alto. $\quad$ Fev. 2016.2 Disponível em: http://agenciabrasil.ebc.com.br/geral/noticia/2016-02/ibge-reve-altitudes-de-sete-picosbrasileiros-pico-da-neblina-fica-mais-alto. Acesso em 15 de abril de 2018.

DOS SANTOS, Camila Mello et al. "Avaliação da qualidade de aprendizagem no ambiente virtual (Moodle) em saúde bucal, na perspectiva dos discentes". Revista da ABENO, v. 18, n. 1, p. 116-123, 2018.

CHIKOFSKY, Elliot; CROSS, James. "Reverse Engineering and Design Recovery: A Taxonomy". IEEE Software, v. 7, n. 1, 1990, p. 13-17.

FILATRO, Andrea. Design instrucional na prática. São Paulo: Pearson Education do Brasil, 2008.

FILATRO, Andrea; CAIRO, Sabrina. Produção de conteúdos educacionais. São Paulo: Saraiva, 2015.

GAMEZ, Luciano. "Reengenharia pedagógica como processo de transformação de 
disciplinas presenciais para a modalidade de educação a distância". In: 4 Seminário Nacional ABED de Educação a Distância, 2006, Brasília. Apresentações Trabalhos Científicos, 2006.

HAMMER, M. \& CHAMPY, J. Reengenharia: repensando a empresa em função dos clientes, da concorrência e das grandes mudanças da gerência. Rio de Janeiro: Campus, $1^{\text {a }}$ ed, 1994.

Jornal Nacional. IBGE mostra números dramáticos do mercado de trabalho em 2016. Fev. 2017. Disponível em: http://g1.globo.com/jornal-nacional/noticia/2017/02/ibgemostra-numeros-dramaticos-do-mercado-de-trabalho-em-2016.html. Acesso em 15 de abril de 2018.

Jornal do Brasil. IBGE: Mulher estuda mais, trabalha mais e ganha menos do que o homem. Mar. 2018. Disponível em: http://www.jb.com.br/pais/noticias/2018/03/07/ibgemulher-estuda-mais-trabalha-mais-e-ganha-menos-do-que-o-homem/. Acesso em 15 de abril de 2018.

LEAL, Janaina. "Reengenharia em bibliotecas". RDBCl: Revista Digital de Biblioteconomia e Ciência da Informação, v. 8, n. 1, p. 12-20, 2010.

MESSIAS, Inês; MORGADO, Lina. "Facebook, educação a distância e envolvimento do estudante". Researchgate.net, 2018. Acesso em 06/04/2018.

O Globo. Concluir o ensino superior triplica a renda, mostra IBGE. Abr. 2018. Acesso em 15 de abril de 2018.

PALANGE, Ivete. "Produção de Design instrucional para EAD: aprendizagem autodirigida, aprendizagem colaborativa, conectivismo e modelo ADDIE". In: KENSKI, Vani Moreira. Design Instrucional para cursos on-line. São Paulo, Senac, 2015.

PISKURICH, George. Rapid instructional design. San Francisco. CA: Pfeiffer, 2006.

SANTOS, Cristiane. "Processo de criação de storyboard'. In: KENSKI, Vani Moreira. Design Instrucional para cursos on-line. São Paulo, Senac, 2015. 